Analisis Peningkatan Dinas Jaga di Daerah Rawan Guna Meningkatkan Keamanan

Pada Kapal MT. Sei Pakning

Dwi Antoro $^{\mathrm{a}}$, Sri Purwantini ${ }^{\mathrm{b}}$ dan M. Arif Ikhsannudin ${ }^{\mathrm{c}}$

\title{
ANALISIS PENINGKATAN DINAS JAGA DI DAERAH RAWAN GUNA MENINGKATKAN KEAMANAN PADA KAPAL MT. SEI PAKNING
}

\author{
Dwi Antoro $^{a}$, Sri Purwantini ${ }^{\mathrm{b}}$ dan M. Arif Ikhsannudin ${ }^{\mathrm{c}}$ \\ ${ }^{a}$ Dosen Program Studi Nautika PIP Semarang \\ ${ }^{\mathrm{b}}$ Dosen Program Studi KALK PIP Semarang \\ ${ }^{c}$ Taruna (NIT.49124420.N) Program Studi Nautika PIP Semarang
}

\begin{abstract}
ABSTRAK
Dinas jaga pelabuhan di kapal dilaksanakan ketika kapal sedang berlabuh jangkar, sandar dermaga atau diikat di buoy, olah gerak untuk berangkat dari pelabuhan maupun tiba di pelabuhan, bongkar muat, dan menerima atau menurunkan pandu. Dinas jaga berfungsi untuk menciptakan keamanan di kapal dan lingkungan. Pelaksanaan dinas jaga tidak maksimal disebabkan karena peralatan penunjang keamanan yang kurang dan penerapan ISPS Code yang tidak maksimal. Dan hal tersebut dapat diatasi dengan menyediakan peralatan penunjang keamanana dan ISPS Code diterapkan secara maksimal di atas kapal.

Penelitian ini menggunakan metode deskriptif kualitatif dengan USG untuk menentukan prioritas masalah. Permasalahan yang terjadi adalah pelaksanaan dinas jaga yang tidak maksimal di daerah rawan yang berpengaruh terhadap keamanan di kapal MT. Sei Pakning. Maka rumusan masalah dari masalah tersebut adalah bagaimana pelaksanaan dinas jaga di daerah rawan oleh crew MT. Sei Pakning dan bagaimana upaya yang harus dilakukan untuk meningkatkan keamanan di daerah rawan.

Dari hasil penelitian yang menyebabkan kurang efektifnya pelaksanaan dinas jaga di daerah rawan di kapal MT. Sei Pakning adalah peralatan penunjang keamanan seperti handy talky, senter, pentungan yang tidak ada, CCTV yang trouble. Dan pelaksanaan ISPS Code yang tidak diterapkan secara baik di atas kapal. Dari masalah-masalah tersebut yang menjadi penyebab kurang maksimalnya pelaksanaan dinas jaga di daerah rawan. Upaya yang dilakukan meningkatkan keamanan adalah dengan menyediakan peralatan penunjang keamanan, perbaikan, penyediaan CCTV oleh kontraktor, pengawasan, pembuatan checklist, training kepada crew dan penambahan personil yang melakukan dinas jaga.
\end{abstract}

Kata kunci : dinas jaga, USG, dan ISPS Code

\section{PENDAHULUAN}

\section{A. Latar Belakang}

Dinas kapal pada umumnya terbagi menjadi 2 (dua) yakni dinas harian dan dinas jaga. Dinas harian merupakan kegiatan atau aktifitas yang dilaksanakan pada jam kerja baik di laut maupun di pelabuhan oleh semua anak buah kapal. Adapun kegiatan yang dilakukan dalam dinas harian adalah administrasi di kapal, pemeliharaan atau perawatan kapal berserta peralatan yang ada di atas kapal, urusan anak buah kapal, urusan muatan atau penumpang, sedangkan dinas jaga merupakan kegiatan atau aktifitas yang dilaksanakan oleh regu jaga yang dipimpin oleh seorang perwira jaga di atas kapal. Tujuan dilaksanakan dinas jaga adalah untuk menjaga keamanan, ketertiban, dan kebersihan kapal, muatan, penumpang, lingkungan, dan untuk melaksanakan peraturan-peraturan, perintah atau instruksi 
yang berlaku. Dalam pelaksanaannya dinas jaga di kapal terbagi menjadi Jaga Laut dan Jaga Pelabuhan.

Dinas jaga pelabuhan di kapal dilaksanakan ketika kapal sedang berlabuh jangkar, sandar dermaga atau diikat di buoy, olah gerak untuk berangkat dari pelabuhan maupun tiba di pelabuhan, bongkar muat, dan menerima/menurunkan pandu. Adapun halhal yang berkaitan dengan keamanan di area pelabuhan harus sesuai dengan ISPS Code diharuskan sebagai perwira jaga mengetahuai tentang pelaksanaan dinas jaga dan pencegahan ancaman guna menciptakan keamanan di kapal.

Dinas jaga pelabuhan harus dilaksanakan dengan maksimal, khususnya pada daerah rawan yang sangat beresiko terjadinya ancaman keamanan, maka dilaksanakan sesuai dengan safety of life at sea (SOLAS) yang terkait dengan, langkah-langkah khusus untuk meningkatkan keamanan maritime, kode keamanan internasional untuk kapal dan pelabuhan (ISPS Code) bagian A dan B. ISPS Code. Langkah-langkah khusus untuk meningkatkan keamanan maritim dalam Konvensi Internasional untuk Keselamatan Jiwa di Laut (SOLAS). Tujuan dari kode ini adalah menyediakan standar, kerangka kerja yang konsisten untuk mengevaluasi risiko, memungkinkan Pemerintah untuk mengimbangi apabila terjadi perubahan ancaman dengan merubah nilai kerentanan pada kapal dan fasilitas pelabuhan melalui penentuan tingkat keamanan yang sesuai dan langkah-langkah keamanan yang sesuai dan pencegahan yang sesuai.

Selama penulis melakukan penelitian di atas kapal penulis menemukan adanya permasalahan-permasalahan yang berkaitan dengan penerapan ISPS Code yang tidak maksimal dan pelaksanaan dinas jaga yang kurang efektif, khususnya daerah rawan. Untuk memastikan bahwa langkah-langkah untuk mengatasi segala ancaman bahaya keamanan fasilitas pelabuhan, kapal, muatan dan untuk melindungi crew kapal, beserta barang miliknya maka berdasarkan latar belakang tersebut, maka penulis memilih judul "ANALISIS PENINGKATAN DINAS JAGA DI DAERAH RAWAN GUNA MENINGKATKAN KEAMANAN PADA KAPAL MT. SEI PAKNING".

\section{B. Perumusan Masalah}

Berdasarkan uraian latar belakang yang telah di kemukakan di atas, maka rumusan permasalahan penelitian ini sebagai berikut:

1. Bagaimana pelaksanaan dinas jaga di daerah rawan oleh crew MT. Sei Pakning?

2. Bagaimana upaya yang harus dilakukan untuk meningkatkan keamanan di daerah rawan?

\section{Tujuan Penelitian}

Tujuan penelitian ini adalah sebagai berikut untuk:

1. Untuk mengetahui bagaimana pelaksanaan dinas jaga di daerah rawan oleh crew MT. Sei Pakning?

2. Untuk mengetahui upaya yang harus dilakukan untuk meningkatkan keamanan di daerah rawan?

\section{KAJIAN PUSTAKA}

\section{A. Kajian Pustaka}

\section{Analisis}

Menurut Jogiyanto (2010:129) analisis dapat didefinisikan sebagai penguraian dari suatu sistem informasi yang utuh ke dalam bagian-bagian komponennya dengan maksud untuk mengidentifikasi dan mengevaluasi permasalahan, kesempatan, hambatan yang terjadi dan kebutuhan yang terjadi dan kebutuhan yang diharapkan sehingga dapat diusulkan perbaikannya.

\section{Peningkatan}

Pengertian peningkatan secara etimologi adalah menaikan derajat taraf dan sebagainya mempertinggi memperhebat produksi dan sebagainya, proses cara perbuatan meningkatkan usaha kegiatan dan sebagainya. 
Analisis Peningkatan Dinas Jaga di Daerah Rawan Guna Meningkatkan Keamanan

Pada Kapal MT. Sei Pakning

Dwi Antoro $^{\mathrm{a}}$, Sri Purwantini ${ }^{\mathrm{b}}$ dan M. Arif Ikhsannudin ${ }^{\mathrm{c}}$

\section{Dinas Jaga}

Menurut Djoko Subandrijo (2011:67) pelaksanaan dinas jaga yang dilakukan oleh petugas jaga navigasi atau tugas jaga dek, harus memenuhi syarat sesuai dengan ketentuan-ketentuan yang berkaitan dengan jaga navigasi atau jaga dek. Pada waktu kapal sedang berlayar maupun kapal sandar di pelabuhan:

a. Dinas harian

1) Dilakukan pada hari-hari kerja sedangkan hari minggu dan hari besar libur.

2) Tugas-tugas yang dilakukan meliputi tugas administrasi dan perawatan operasional kapal, sesuai jabatan dan tanggung jawab masing-masing personil.

b. Dinas jaga

1) Dinas jaga navigasi

Dinas jaga navigasi adalah dinas jaga selama kapal dalam keadaan berlayar, dimana mesin penggerak utama jalan. Dinas jaga ini dimulai sejak perintah nakhoda one hour noutice satu jam untuk manouver atau mengolah gerak atau berangkat dari pelabuhan dan berakhir pada perintah Finish With Engine saat kapal tiba di pelabuhan tujuan ini adaah perintah nakhoda kepada seluruh awak kapalnya agar mulai mempersiapkan semua peralatan dan permesinan untuk manouvering. Secara umum pengaturan tugas jaga navigasi di kapal dilaksanakan sebagai berikut:

a) Jam 00.00-04.00 Jaga Mualim II

b) Jam 04.00-08.00 Jaga Mualim I

c) Jam 08.00-12.00 Jaga Mualim III

d) Jam 12.00-16.00 Jaga Mualim II

e) Jam 16.00-20.00 Jaga Mualim I

f) Jam 20.00-00.00 Jaga Mualim III
2) Dinas jaga pelabuhan

Dinas jaga pelabuhan adalah dinas jaga pada saat kapal berada di pelabuhan. Pada saat kapal yang sandar dengan aman sesuai situasi-situasi normal di pelabuhan, Nakhoda harus mengatur agar tugas jaga yang memadai dan efektif tetap dijalankan untuk tujuan keselamatan. Persyaratanpersaratan mungkin diperlukan untuk jenis-jenis khusus sistem penggerak kapal atau peralatan bantu, untuk membawa muatan berbahaya, beracun atau mudah terbakar, atau jenis-jenis khusus muatan lain. Petugas jaga di pelabuhan terdiri dari: perwira jaga dibantu oleh juru mudi dan kelasi. Tugas jaga di pelabuhan dilaksanakan pada saat:

a) Kapal sedang berlabuh jangkar.

b) Kapal sedang sandar di dermaga dan kapal terkepil pada pelampung kepil.

c) Kapal sedang berolah gerak tiba di pelabuhan dan berangkat dari pelabuhan.

d) Kapal sedang melakukan muat bongkar.

e) Kapal menerima/ menurunkan pandu.

\section{Daerah Rawan}

Menurut Hikmahanto (2007:102) daerah rawan adalah daerah yang terjadi tindak pembajakan dan pencurian. Diharapkan kapal-kapal waspada saat berada di daerah tersebut, diharapkan pemerintah dapat mengumumkan dan menghimbau para nakhoda kapal untuk meningkatkan kewaspadaan di daerah tersebut mengingat wilayah tersebut tidak aman. Asia Tenggara, sebagaimana 
layaknya nation-state, masih menganggap penting keamanan tradisional, yaitu keamanan terhadap teritori negara. Termasuk didalamnya adalah keamanan domestik dan internasional.

\section{Keamanan}

Menurut Kamus Besar Bahasa Indonesia (2008:48) Keamanan adalah keadaan aman bebas dari bahaya tidak mengungsi ke tempat aman dalam situasi perang, banjir, wabah penyakit, bebas dari gangguan pencuri. Terlindung tidak merasa takut atau khawatir terhadap kejahatan, bahaya, mencegah orang yang melanggar hukum demi keamanan dirinya atau lingkungan.

\section{B. Kerangka Pikir}

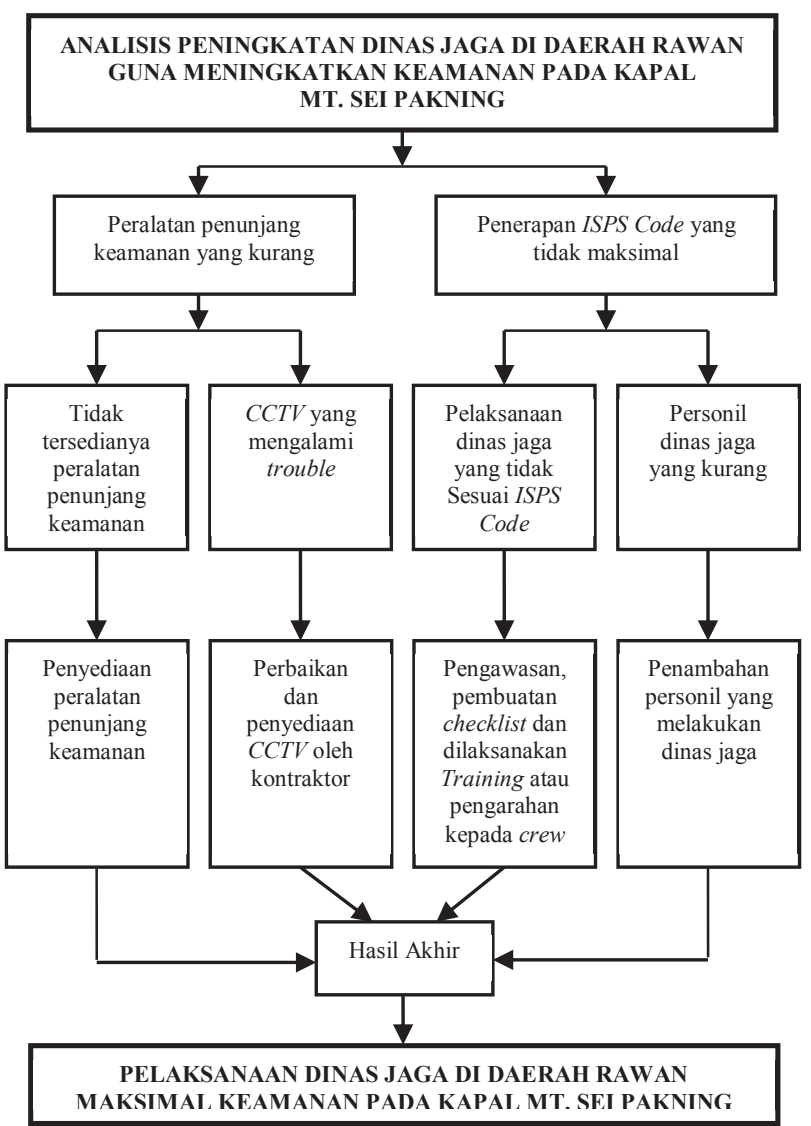

\section{METODOLOGI}

\section{A. Metode Penelitian}

Menurut Juliansyah (2009:147), penelitian deskriptif adalah penelitian yang berusaha mendriskripsikan suatu gejala, peristiwa, kejadian yang terjadi saat sekarang. Penelitian deskriptif memusatkan perhatian pada masalah aktual sebagaimana adanya pada saat penelitian berlangsung. Melalui penelitian deskriptif, peneliti berusaha mendeskripsikan peristiwa dan kejadian yang menjadi pusat perhatian tanpa memberikan pelakuan khusus terhadap peristiwa tersebut. Variabel yang diteliti bisa tunggal (satu variabel) bisa juga lebih dari satu variabel. Penelitian deskriptif sesuai karakteristik memiliki langkahlangkah tertentu dalam pelaksanaannya, langkah-langkah ini sebagai berikut :

1. Diawali dengan adanya masalah;

2. Menentukan jenis informasi yang diperlukan;

3. Menentukan prosedur pengumpulan data melalui observasi atau pengamatan;

4. Pengolahan informasi atau data;

5. Menarik kesimpulan penelitian.

Menurut Sugiyono (2009:9), penelitian kualitatif adalah metode penelitian yang berlandaskan pada filsafat. Digunakan untuk meneliti pada kondisi objek yang alamiah, dimana peneliti adalah sebagai instrumen kunci. Teknik pengumpulan data dilakukan secara gabungan, analisis data bersifat induktif atau kualitatif, dan hasil penelitian kualitatif lebih menekankan makna dari pada generalisasi. Metode penelitian kualitatif yang digunakan adalah bersifat deskriptif yang artinya menggambarkan dan menguraikan suatu objek yang akan diteliti.

\section{B. Waktu Dan Tempat Penelitian}

1. Waktu Penelitian

Penelitian dilakukan selama 13 (tiga belas) bulan, 9 (sembilan) hari 
Analisis Peningkatan Dinas Jaga di Daerah Rawan Guna Meningkatkan Keamanan Pada Kapal MT. Sei Pakning

Dwi Antoro ${ }^{\mathrm{a}}$, Sri Purwantini ${ }^{\mathrm{b}}$ dan M. Arif Ikhsannudin ${ }^{\mathrm{c}}$

ketika masa praktek laut berlangsung, yaitu tehitung tanggal 23 Maret 2015 sampai dengan tanggal 02 Mei 2016.

\section{Tempat Penelitian}

Penelitian ini dilakukan selama melaksanakan praktek laut di kapal MT. Sei Pakning. Kapal milik perusahaan PT. Pertamina yang beralamat di Jl. Medan Merdeka Timur 1A, Gedung Perwira 2 Lantai 1, Jakarta Pusat 10110. Pelaksanaan penelitian dilakukan pada saat kapal berada di Pelabuhan Tanjung Perak, Surabaya.

\section{Data Yang Digunakan}

Metode penelitian pada dasarnya merupakan cara ilmiah untuk mendapatkan data. Data merupakan tahapan yang penting dalam proses penelitian, karena hanya dengan mendapatkan data yang tepat maka proses penelitian akan berlangsung sampai peneliti mendapatkan jawaban dari perumusan masalah yang sudah ditetapkan. Data yang kita cari harus sesuai dengan tujuan penelitian. Berdasarkan cara memperolehnya, data yang diperoleh selama penelitian sebagai pendukung tersusunnya penulisan penelitian ini adalah:

1. Data primer

Menurut S. Margono (2008:23), data primer adalah data yang dikumpulkan langsung dari individuindividu yang diteliti, dikumpulkan oleh peneliti secara langsung dari sumber data utama atau objek penelitian. Data primer disebut juga sebagai data asli atau data baru, memiliki sifat up to date. Untuk mendapatkan data primer, peneliti harus mengumpulkannya secara langsung.

Data primer dalam penelitian ini diperoleh melalui pengamatan langsung pada objek-objek penelitian di kapal MT. Sei Pakning dan melalui wawancara-wawancara pada pihakpihak yang terkait pada penelitian.

\section{Data Sekunder}

Menurut S. Margono (2008:23), data sekunder adalah data yang ada dalam studi pustaka atau studi literatur, arsip-arsip, gambar dan foto-foto. Data sekunder dalam penelitiaan dibagi menjadi Studi Dokumentasi dan Studi Pustaka. Studi dokumentasi diperoleh melalui Foto-foto dan gambar-gambar. Studi pustaka ini diperoleh dari buku IMO, STCW dan ISPS Code.

\section{Metode Pengumpulan Data}

Di dalam penelitian ini penulis menggunakan beberapa metode pengumpulan data antara lain :

1. Observasi

Menurut Sugiyono (2009:145), observasi digunakan bila, penelitian berkenaan dengan perilaku manusia, proses kerja, gejala-gejala alam dan bila responden yang diamati tidak terlalu besar. Dari segi proses pelaksanaan pengumpulan data. Observasi dapat dibedakan menjadi participant observation (observasi berperan serta) dan non participant observation, selanjutnya dari segi instrumentasi yang digunakan, maka observasi dapat dibedakan menjadi observasi terstruktur dan tidak terstruktur.

Observasi dalam penelitian ini adalah participant observation (observasi berperan serta), dimana peneliti terlibat dengan kegiatan sehari-hari orang yang sedang diamati atau yang digunakan sebagai sumber data penelitian. Peneliti terlibat langsung dalam pengamatan dan andil bagian atau berperan serta dalam kegiatan. 
2. Wawancara

Menurut Sugiyono (2009:137), wawancara adalah proses memperoleh penjelasan untuk mengumpulkan informasi-informasi dengan menggunakan cara tanya jawab, bisa dilakukan sambil bertatap muka secara langsung, melalui media telekomunikasi antar pewawancara dengan orang yang diwawancarai, dengan atau tanpa menggunakan pedoman. Pada hakikatnya wawancara merupakan kegiatan untuk memperoleh informasi secara mendalam tentang sebuah isu atau tema yang diangkat dalam penelitian atau merupakan proses pembuktian terhadap informasi atau keterangan yang telah diperoleh.

Adapun wawancara dalam penelitian ini dilakukan secara terbuka dan terstruktur, pihak-pihak yang menjadi narasumber pada penelitian ini adalah:

a. Capt. Diwan Adfi Siregar (Nakhoda Kapal MT. Sei Pakning). Sebagai pimpinan, yang bertanggung jawab terhadap seluruh kegiatan di atas kapal, sebagai wakil perusahaan dan sebagai penegak hukum.

b. Toric Aguido Sihotang (Mualim I Kapal MT. Sei Pakning). Sebagai pihak yang membuat jadwal dinas jaga, yang bertanggung jawab terhadap crew kapal dan pelaksanaan dinas jaga berjalan dengan baik di atas kapal MT. Sei Pakning.

c. Fernando Frendji Gandaria (Mualim II Kapal MT. Sei Pakning). Sebagai pihak yang menjadi SSO di atas kapal yang bertanggung jawab terhadap keamanan kapal MT. Sei Pakning.

d. Baso Palonggang (Juru Mudi Kapal MT. Sei Pakning). Sebagai pihak yang terlibat langsung dalam pelaksanaan dinas jaga di kapal MT. Sei Pakning. e. James Dean Umbokahu (Klasi Kapal MT. Sei Pakning). Sebagai pihak yang terlibat langsung dalam pelaksanaan dinas jaga di kapal MT. Sei Pakning.

\section{Dokumentasi}

Dalam upaya mengumpulkan data dengan cara dokumentasi peneliti menelusuri berbagai macam dokumen antara lain ship's particular, crew list, daftar dinas jaga, daftar organisasi keamanan kapal dan foto-foto yang terkait dengan objek penelitian.

4. Metode Kepustakaan

Menurut Supardi (2008:33), studi kepustakaan adalah menelusuri dan mencari dasar-dasar acuan yang erat kaitannya dengan masalah penelitian yang hendak dilakukan, dasar-dasar tersebut tidak terbatas dari satu sumber saja tetapi dapat dicari dari berbagai sumber yang kemudian disusun dalam bab tersendiri. Study Pustaka yang digunakan dalam penelitian adalah buku-buku yang terkait dengan penelitian, seperti International Maritime Organization (IMO), Standards of Training, Certification and Watchkeeping for Seafarers (STCW) dan International Ship and Port Facility Security (ISPS). Bukubuku tersebut sangat mendukung, menunjang dan menjadi dasar materi penelitian yang dilakukan oleh peneliti.

\section{E. Teknik Analisa Data}

Tahap analisa data adalah tahap paling penting dan menentukan dalam suatu penelitian. Analisasi data, menurut Wiratna (2014:103) adalah upaya data yang sudah tersedia kemudian diolah dengan daftar dan dapat digunakan untuk menjawab rumusan masalah dalam penelitian. Dengan demikian, teknis analisis data dengan tujuan mengolah 
data tersebut untuk menjawab rumusan masalah.

Dalam penelitian ini penulis mengunakan lebih dari satu teknik analisis data. Teknik analisis data yang digunakan dalam penelitian ini adalah teknik analisis data kualitatif dan metode matrik USG. Teknis analisis data yang digunakan penulis dalam penelitian yaitu:

1. Teknik analisisi data kualitatif

a. Reduksi data

Dalam proses reduksi data penulis akan memilih hal-hal pokok, memfokuskan pada hal-hal yang penting dan membuang data yang tidak diperlukan. Dengan demikian data yang telah direduksi akan memberikan gambaran lebih jelas mengenai permasalahan penelitian.

b. Penyajian data

Penyajian data yang berupa sekumpulan informasi yang telah tersusun secara terpadu dan mudah dipahami yang memberikan kemungkinan adanya penarikan kesimpulan.

2. Penarikan kesimpulan

Dalam menarik kesimpulan merupakan kemampuan seorang peneliti dalam menyimpulkan berbagai data yang diperoleh selama proses penelitian berlangung.

\section{Metode Matriks USG (Urgency,} Seriousness, Growth).

Dimana Metode Matriks USG adalah suatu metode yang digunakan untuk menentukan suatu masalah yang prioritas, terdapat 3 (tiga) faktor yang perlu dipertimbangkan. Ketiga faktor tersebut adalah urgency, seriousness, dan growth.

Urgency berkaitan dengan mendesaknya waktu yang diperlukan untuk menyelesaikan masalah tersebut.
Semakin mendesak suatu masalah untuk diselesaikan maka semakin tinggi urgency masalah tersebut.

Seriousness berkaitan dengan dampak dari adanya masalah tesebut terhadap organisasi. Dampak ini terutama yang menimbulkan kerugian. Semakin tinggi dampak masalah tersebut terhadap organisasi maka semakin serius masalah tersebut.

Growth berkaitan dengan pertumbuhan masalah. Semakin cepat berkembang masalah tersebut maka semakin tinggi tingkat pertumbuhannya. Suatu masalah yang cepat berkembang tentunya makin prioritas untuk diatasi permasalahannya.

Metode USG merupakan salah satu cara menetapkan urutan prioritas masalah dengan metode teknik scoring. Caranya dengan menentukan Urgency, Seriousness, dan Growth dengan menggunakan skala nilai $1-5$, suatu masalah dengan total skor tertinggi merupakan masalah yang prioritas. Adapun keterangan skor sebagai berikut:

Tabel Skala penilaian metode USG

\begin{tabular}{|c|c|}
\hline Skala & Penilaian \\
\hline 5 & Sangat Besar \\
\hline 4 & Besar \\
\hline 3 & Sedang \\
\hline 2 & Kecil \\
\hline 1 & Sangat Kecil \\
\hline
\end{tabular}

\section{DISKUSI}

\section{A. Gambaran Umum}

PT. Pertamina (Persero) adalah perusahaan milik negara yang bergerak pada sektor logistik yang profesional dalam hal penyediaan minyak, gas bumi, petrokimia dan produk kilang lainnya. 
Pada tanggal 15 Maret 1990 Keputusan Presiden No. 11 (sebelas) menghasilkan terbentuknya direktorat perkapalan kepelabuhanan dan komunikasi yang kemudian menjadi PT. Direktorat Pemasaran, pada tahun 2004 menjadi PT. Pertamina (Persero) yang beralamat di Jl. Yos Sudarso 32-34 Tanjung Priok Jakarta Utara. PT Pertamina Pusat beralamat di Jl. Medan Merdeka Timur 1A, Gedung Perwira 2 (dua) Lantai 1 (satu), Jakarta Pusat 10110. Misi dari perusahaan adalah memfokuskan pada pemberian pelayanan yang terbaik dengan tetap menjaga dan mempertahankan lingkungan alam sekitar. Untuk mencapai misi tersebut, perusahaan telah menciptakan budaya perusahaan yang lebih baik, membangun citra perusahaan yang baru dan menerapkan prinsip transportasi, good corporate governance dan sistem pengawasan internal yang tepat.

Saat ini perusahaan PT. Pertamina (Persero) telah memiliki kurang lebih 50 kapal tanker yang beroperasi dengan berbagai macam tipe yaitu kapal-kapal tanker tipe M, K, P, S, G dan kapal-kapal gas yang di kelompokan berdasarkan ukuran dan nama depan dari setiap tipe kapal-kapal tanker tersebut.

Peneliti melakukan penelitian di kapal MT. Sei Pakning salah 1 (satu) kapal milik PT. Pertamina (Persero) tipe Medium Range tipe S, dengan jenis kapal oil tanker produk yang memuat hasil produk olahan minyak bumi, seperti Premium, HSD, Kerosin maupun Aftur. Route pelayaran MT. Sei Pakning tergantung dari shiping order yang dikirim melalui email yang dikirimkan oleh perusahaan ke email kapal.

Sesuai dengan judul "Analisis peningkatan dinas jaga di daerah rawan guna meningkatkan keamanan di kapal MT. Sei Pakning" maka sebagai diskripsi data akan di jelaskan tentang keadaan sebenarnya yang terjadi di kapal, sehingga dengan deskripsi ini penulis mengharapkan agar pembaca mampu dan bisa merasakan tentang semua hal yang terjadi selama penulis melaksanakan penelitian. Gambar di bawah merupakan gambar kapal tempat penulis melaksanakan praktek laut dan tempat penulis melaksanakan penelitian.

Gambar Kapal MT. Sei Pakning

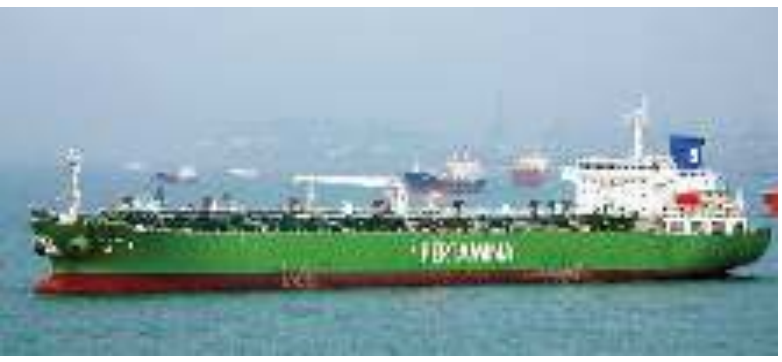

MT. Sei Pakning memiliki nama panggilan (Call Sign), PODV (Papa Oscar Delta Viktor), memiliki Deadweight (DWT) 29.756 Ton, panjang kapal 180,00 meter, lebar 30,49 meter. MT. Sei Pakning di buat di China dan Louncing pada 15 Oktober 2011. Class yang di miliki kapal adalah BKI dan $D N V$, kapal beroperasi di Indonesia, discarging maupun loading dengan pelabuhan yang berbeda beda sesuai dengan shiping order yang di kirim perusahaan ke email kapal. Crew kapal berjumlah 29 (dua puluh sembilan) crew termasuk nakhoda, semua crew kapal berkebangsaan indonesia.

Pentingnya pelaksanaan dinas jaga yang baik untuk menjaga keamanan dan keselamatan jiwa, kapal, muatan dan pelabuhan dari hal-hal yang tidak diinginkan. Penelitian yang dilakukan penulis merupakan suatu bentuk analisis, adapun pengertian dari analisis adalah penyelidikan terhadap suatu peristiwa (perbuatan, karangan dan sebagainya) untuk mendapatkan fakta yang tepat, asalusul, sebab, penyebab sebenarnya, dan sebagainya.

Analisis data yang digunakan adalah metode USG (Urgency, Seriousnes, Growth), untuk menentukan masalah 
Analisis Peningkatan Dinas Jaga di Daerah Rawan Guna Meningkatkan Keamanan Pada Kapal MT. Sei Pakning

Dwi Antoro $^{\mathrm{a}}$, Sri Purwantini ${ }^{\mathrm{b}}$ dan M. Arif Ikhsannudin ${ }^{\mathrm{c}}$

utama atau prioritas masalah dari kurang efektifnya pelaksanaan dinas jaga di daerah rawan di kapal MT. Sei Pakning. Peneliti melakukan survai terhadap crew kapal mengunakan kuisioner atau angket dan dilengkapi juga dengan hasil wawancara dengan beberapa crew kapal untuk menentukan urutan permasalahan penyebab kurang efektifnya pelaksanaan dinas jaga di daerah rawan di kapal MT. Sei Pakning.

Dari survei yang dilakukan melalui kuisioner kepada Mualim I, II dan III. Pertanyaan mengenai masalah-masalah yang menyebabkan kurang efektifnya pelaksanaan dinas jaga di kapal MT. Sei Pakning didapat hasil sebagai berikut :

Tabel Hasil Kuisioner

\begin{tabular}{|c|c|c|c|c|c|c|c|}
\hline \multirow{2}{*}{ NO } & \multirow{2}{*}{ PERNYATAAN } & \multicolumn{5}{|c|}{ SKALA } & \multirow{2}{*}{$\begin{array}{l}\text { TOT } \\
\text { AL }\end{array}$} \\
\hline & & 1 & 2 & 3 & 4 & 5 & \\
\hline 1 & $\begin{array}{l}\text { Peralatan penunjang } \\
\text { keamanan yang kurang }\end{array}$ & & & & $\begin{array}{l}\text { I } \\
\text { I }\end{array}$ & I & 13 \\
\hline 2 & $\begin{array}{l}\text { Penerapan ISPS Code } \\
\text { yang tidak maksimal }\end{array}$ & & & I & I & I & 12 \\
\hline 3 & $\begin{array}{l}\text { Pengetahuan dan } \\
\text { kesadaran crew yang } \\
\text { kurang tentang keamanan } \\
\text { di daerah rawan }\end{array}$ & & & I & $\begin{array}{l}\text { I } \\
\text { I }\end{array}$ & & 11 \\
\hline 4 & $\begin{array}{l}\text { Disiplin personil dinas } \\
\text { jaga }\end{array}$ & & $\mathrm{I}$ & I & I & & 9 \\
\hline 5 & Security patrol & & $\begin{array}{l}\mathrm{I} \\
\mathrm{I}\end{array}$ & & I & & 8 \\
\hline 6 & $\begin{array}{l}\text { Waktu istirahat personil } \\
\text { dinas jaga }\end{array}$ & & $\begin{array}{l}\text { I } \\
\text { I }\end{array}$ & I & & & 7 \\
\hline 7 & Perancanaan dinas jaga & I & I & $\mathrm{I}$ & & & 6 \\
\hline
\end{tabular}

Dari hasil Kuisioner yang dilakukan peneliti terhadap Mualim I, II dan III didapat urutan masalah sebagai berikut :

1. Peralatan penunjang keamanan yang kurang;

2. Penerapan ISPS Code yang tidak maksimal;

3. Pengetahuan dan kesadaran crew yang kurang tentang keamanan di daerah rawan;
4. Disiplin personil dinas jaga;

5. Security Patrol;

6. Waktu istirahat personil dinas jaga;

7. Perancanaan dinas jaga.

Hasil dari kuisioner kemudian dilakukan analisis data mengunakan metode USG untuk menentukan skor tiaptiap masalah. Metode USG pada prinsipnya merupakan pendekatan untuk mengidentifikasi prioritas penyebab masalah, pendekatan ini dapat digunakan untuk mengidentifikasi masalah utama atau prioritas masalah yang berpotensi sebagai faktor penyebab kurang efektifnya pelaksanaan dinas jaga di daerah rawan di kapal MT. Sei Pakning. USG mempunyai 3 (tiga) klasifikasi prioritas permasalahan yaitu: Urgency (U), Seriousnes (S) dan Growth (G).

Dengan mengetahuai masalah utama atau masalah prioritas tersebut, maka dapat diambil tindakan-tindakan yang dilakukan untuk mencegah kurang efektifnya pelaksanaan dinas jaga di daerah rawan di kapal MT. Sei Pakning. Agar pelaksanaan dinas jaga dapat berjalan baik dan maksimal sehingga keamanan di atas kapal akan meningkat.

Bardasarkan survei yang dilakukan peneliti kepada para perwira di atas kapal menggunakan angket atau kuisioner didapat data kemudian data tersebut diperoleh dengan mengunakan metode USG untuk mengetahui total nilai dari masing-masing masalah, maka dapat dilakukan urutan peroritas masalah berdasarkan nilai tebesar atau tertinggi. Nilai yang paling besar atau tertinggi adalah prioritas yang perlu segera dilaksanakan, dan demikian seterusnya sampai nilai terendah yaitu prioritas yang paling tidak mendesak untuk segera diselesaikan. Masalah utama atau masalah mendesak harus segera diselesaikan dan dicari pemecahan masalahnya agar masalah mengenai kurang efektifnya pelaksanaan dinas jaga di daerah rawan 
dapat segera dicari solusi pemecahan masalah-masalahnya. Untuk lebih jelasnya menentukan masalah utama atau prioritas masalah dapat dilihat pada tabel analisis perbandingan USG di bawah ini:

Tabel Analisis USG

\begin{tabular}{|c|c|c|c|c|c|c|c|c|c|c|}
\hline \multirow{2}{*}{$\begin{array}{l}\mathbf{N} \\
\mathbf{O}\end{array}$} & \multirow{2}{*}{$\begin{array}{c}\text { MASALA } \\
\text { H }\end{array}$} & \multirow{2}{*}{$\begin{array}{l}\text { ANALISIS } \\
\text { PERBAN } \\
\text { DINGAN }\end{array}$} & \multirow{2}{*}{$\mathbf{U}$} & \multirow{2}{*}{$\mathbf{S}$} & \multirow{2}{*}{ G } & \multicolumn{4}{|c|}{ NILAI } & \multirow{2}{*}{$\begin{array}{c}\text { PRI } \\
\text { O } \\
\text { RIT } \\
\text { AS } \\
\end{array}$} \\
\hline & & & & & & $\mathbf{U}$ & $\mathbf{S}$ & $\mathbf{G}$ & $T$ & \\
\hline $\mathbf{A}$ & $\begin{array}{l}\text { Peralatan } \\
\text { penunjan } \\
\text { g } \\
\text { keamanan } \\
\text { yang } \\
\text { kurang }\end{array}$ & $\begin{array}{l}\text { A-B } \\
\text { A-C } \\
\text { A-D } \\
\text { A-E } \\
\text { A-F } \\
\text { A-G }\end{array}$ & $\begin{array}{l}\text { A } \\
\mathbf{B} \\
\mathbf{A} \\
\mathbf{A} \\
\mathbf{A} \\
\mathbf{G}\end{array}$ & $\begin{array}{l}\text { A } \\
\text { A } \\
\text { D } \\
\text { E } \\
\text { A } \\
\text { A }\end{array}$ & $\begin{array}{l}\text { A } \\
\text { C } \\
\text { A } \\
\text { E } \\
\text { F } \\
\text { A }\end{array}$ & 4 & 5 & 4 & 11 & I \\
\hline B & $\begin{array}{l}\text { Penerapa } \\
\text { n ISPS } \\
\text { Code } \\
\text { yang } \\
\text { tidak } \\
\text { maksima } \\
\text { l }\end{array}$ & $\begin{array}{l}\text { B-C } \\
\text { B-D } \\
\text { B-E } \\
\text { B-F } \\
\text { B-G }\end{array}$ & $\begin{array}{l}\text { B } \\
\text { B } \\
\text { B } \\
\text { B } \\
\text { G }\end{array}$ & $\begin{array}{l}\text { B } \\
\text { D } \\
\text { B } \\
\text { B } \\
\text { B }\end{array}$ & $\begin{array}{l}\text { C } \\
\text { B } \\
\text { E } \\
\text { B } \\
\text { G }\end{array}$ & 4 & 4 & 2 & 10 & II \\
\hline C & $\begin{array}{l}\text { Pengetahu } \\
\text { an dan } \\
\text { kesadaran } \\
\text { crew yang } \\
\text { kurang } \\
\text { tentang } \\
\text { keamanan } \\
\text { di daerah } \\
\text { rawan }\end{array}$ & $\begin{array}{l}\text { C-D } \\
\text { C-E } \\
\text { C-F } \\
\text { C-G }\end{array}$ & \begin{tabular}{l|}
$\mathbf{C}$ \\
$\mathbf{C}$ \\
$\mathbf{C}$ \\
$\mathbf{C}$
\end{tabular} & $\begin{array}{l}\text { D } \\
\text { C } \\
\text { C } \\
\text { C }\end{array}$ & $\begin{array}{l}\text { C } \\
\text { E } \\
\text { C } \\
\text { G }\end{array}$ & 4 & 3 & 2 & 9 & III \\
\hline D & $\begin{array}{l}\text { Disiplin } \\
\text { personil } \\
\text { dinas jaga }\end{array}$ & $\begin{array}{l}\text { D-E } \\
\text { D-F } \\
\text { D-G }\end{array}$ & $\begin{array}{l}\text { D } \\
\text { D } \\
\text { D }\end{array}$ & $\begin{array}{l}\text { E } \\
\text { D } \\
\text { D }\end{array}$ & $\begin{array}{l}\text { D } \\
\text { D } \\
\text { G }\end{array}$ & 3 & 2 & 2 & 7 & IV \\
\hline $\mathbf{E}$ & $\begin{array}{l}\text { Security } \\
\text { patrol }\end{array}$ & $\begin{array}{l}\text { E-F } \\
\text { E-G }\end{array}$ & $\begin{array}{l}\mathbf{E} \\
\mathbf{E}\end{array}$ & $\begin{array}{l}\mathbf{E} \\
\mathbf{E}\end{array}$ & $\begin{array}{l}\text { E } \\
\text { G }\end{array}$ & 2 & 2 & 1 & 5 & $\mathbf{V}$ \\
\hline $\mathbf{F}$ & $\begin{array}{l}\text { Waktu } \\
\text { istirahat } \\
\text { personil } \\
\text { dinas jaga }\end{array}$ & F-G & $\mathbf{F}$ & $\mathbf{F}$ & G & 1 & 1 & - & 2 & VI \\
\hline G & $\begin{array}{l}\text { Perancan } \\
\text { aan dinas } \\
\text { jaga }\end{array}$ & $\mathbf{G}$ & - & - & G & - & - & 1 & 1 & VII \\
\hline
\end{tabular}

Berdasarkan Tabel Analisis perbandingan USG masalah yang menempati urutasn prioritas pertama 1 (satu) adalah peralatan penunjang keamanan yang mempunyai total skor sebesar 11 (sebelas), dan yang menempati prioritas masalah ke 2 (dua) adalah penerapan ISPS Code yang tidak maksimal yang mempunyai total skor sebesar 10 (sepuluh). Dengan demikian masalah umum atau prioritas masalah adalah:

1. Peralatan penunjang keamanan yang kurang.

2. Penerapan ISPS Code yang tidak maksimal.

\section{B. Analisis Masalah}

Berdasarkan Tabel Analisis USG, penulis mendapatkan analisis penyebab kurang efektif pelaksanaan dinas jaga di daerah rawan oleh crew MT. Sei Pakning saat kapal berada di Pelabuhan Tanjung Perak Surabaya. Berikut faktor-faktor yang menyebabkan kurang efektifnya pelaksanaan dinas jaga di daerah rawan :

1. Peralatan penunjang keamanan yang kurang

a. Tidak tersedianya peralatan penunjang

1) Jumlah HT (Handy Talky) yang terbatas

Jumlah HT (handy talky) yang terbatas dikarenakan HT (Handy Talky) yang jumlahnya sedikit dan ada yang rusak. Jumlah yang terbatas menyebabkan tidak mencukupi semua crew yang ada di atas kapal. Tidak semua perpersonil dinas jaga membawa handy talky (HT) satu per satu hanya Mualim jaga dan juru mudi jaga yang membawa handy talky (HT) karena jumlahnya yang terbatas. Handy talky (HT) banyak yang mengalami kerusakan di baterai yang sering drop atau lowbed, dan antena handy talky (HT) yang hilang dan patah. Handy talky (HT) berperan penting dalam berkomunikasi antar personil dinas jaga. Komunikasi yang kurang terhadap para personil dinas jaga menyebabkan pelaksanaan dinas jaga kurang maksimal.

2) Senter yang rusak

Senter yang rusak akibat perawatan yang kurang, kerusakan senter terjadi di bolam lampu dan per tempat menaruh baterai yang karatan. Per berkarat karena baterai yang dayanya sudah habis tidak langsung diganti, dan diletakkan sembarangan di luar akomodasi setelah digunakan. 
Analisis Peningkatan Dinas Jaga di Daerah Rawan Guna Meningkatkan Keamanan Pada Kapal MT. Sei Pakning

Dwi Antoro a, Sri Purwantini dan M. Arif Ikhsannudin ${ }^{\mathrm{c}}$

3) Pentungan yang tidak tersedia

Pentungan digunakan untuk memebela diri ketika ada pencuri, penjahat, dan orang yang berniat buruk untuk membela diri. Pentungan yang tidak tersedia di atas kapal karena terjatuh ke laut saat diletakkan di reling kapal dan ada ombak saat berlayar.

b. Closed Circuit Television (CCTV) yang mengalami trouble

Closed circuit television (CCTV) yang mengalami trouble akibat dari pemasangan yang tidak sempurna dan tidak maksimal oleh pihak kontraktor, menyebabkan kontrol CCTV yang tidak berfungsi, gambar yang berkedip-kedip dan tidak muncul gambar di layar monitor adalah kendala-kendala yang ada di perangkat CCTV. CCTV yang trouble menyebabkan pengawasan ke seluruh bagian yang dipasang kamera CCTV tidak maksimal.

2. Penerapan ISPS Code yang tidak maksimal

a. Pelaksanaan dinas jaga yang tidak sesuai ISPS Code

Pelaksanaan dinas jaga yang tidak sesuai ISPS Code karena personil dinas jaga tidak melakukan prosedur ISPS Code dengan benar, personil dinas jaga tidak melakukan pemeriksaaan menyeluruh terhadap loading master, surveyor dan para buruh yang memasang loading up yang datang ke kapal, pengecekan barang bawaan, pencocokan identitas diri, KTP ataupun passport dan diganti dengan visitor card yang disesuaikan dengan keperluan dari setiap tamu yang naik ke atas kapal.

b. Personil dinas jaga yang kurang

Pada tingkat siaga 2 atau daerah rawan jumlah personil dinas jaga masih kurang dan dalam proses pelaksanaan dinas jaga pada saat melaksanakan security patrol para personil dinas masih melaksanakan security patrol seperti di daerah aman durasi waktu tidak ditingkatkan sesuai status security level yang diterapkan di daerah rawan.

\section{Pembahasan Masalah}

Berdasarkan Tabel Analisis USG masalah utama atau prioritas masalah yaitu: Pertama peralatan penunjang keamanan yang kurang dan ke 2 (dua) penerapan ISPS Code yang tidak maksimal. Dari ke 2 (dua) masalah prioritas tersebut yang menjadi penyebab kurang efektifnya pelaksanaan dinas jaga di daerah rawan di kapal MT. Sei Pakning pada saat kapal berada di pelabuhan Tanjung Perak Surabaya.

Bagaimana pelaksanaan dinas jaga di daerah rawan oleh crew MT. Sei Pakning?

1. Peralatan penunjang keamanan yang kurang

Penyelesaian masalah dari peralatan penunjang keamanan yang kurang adalah pertama penyediaan peralatan penunjang keamanan. Kedua pengawasan, pemberian sangsi kepada yang melanggar dan melaporkan ke kantor agar CCTV diperbaiki oleh kontraktor.

a. Penyediyaan peralatan penunjang keamanan

1) Handy talky (HT)

Pengunaan handy talky sangat penting dan mendukung dalam pelaksanaan dinas jaga untuk berkomunikasi kepada para personil jaga. Handy talky adalah alat berkomunikasi dengan menggunakan sinyal frekuensi tertentu sebagai pemancarnya untuk menghubungkan handy talky (HT) yang satu dengan handy talky (HT) yang lain. Handy talky 
biasanya digunakan oleh kepolisian ataupun security dengan mengunakan bahasa isyarat dalam berbicara.

Masalah handy talky (HT) yang terjadi di atas kapal adalah jumlahnya yang sedikit, dan tidak mencukupi semua crew yang ada di atas kapal. Tidak semua perpersonil dinas jaga membawa handy talky (HT) satu persatu hanya Mualim jaga dan juru mudi jaga yang membawa handy talky (HT) karena jumlahnya yang terbatas. Handy talky (HT) banyak yang mengamai kerusakan di baterai yang sering drop atau lowbed, dan antena handy talky (HT) yang hilang dan patah. Handy talky (HT) berperan penting dalam berkomunikasi antar personil dinas jaga. Komunikasi yang kurang terhadap para personil dinas jaga menyebabkan pelaksanaan dinas jaga kurang maksimal. Seharusnya personil dinas jaga membawa satu orang satu agar dalam pelaksanaan dinas jaga dalam pemantauan atau menyampaikan informasi dapat dilaporkan segera dan dapat diketahui oleh para personil dinas jaga, kemudian perwira dapat mengambil tindakan yang harus dilakukan, dan keselamatan para personil dinas jaga dapat tidak terancam.

Upaya yang harus dilakukan untuk menyelesaikan permasalahan handy talky (HT) adalah dengan memperbaiki handy talky (HT) yang rusak ke tempat servis handy talky (HT), membuat permintaan barang yang dikirim ke kantor dan dengan membeli handy talky (HT) baru. Mempersiapkan sparepart seperti baterai cadangan antena, dan handy talky (HT) baru di store. Apabila ada handy talky (HT) dapat segera diperbaiki dan apabila handy talky
(HT) ada yang mengalami kerusakan dapat segera diganti dengan handy talky (HT) baru, sehingga pelaksanaan dinas jaga tetap berjalan dengan optimal.

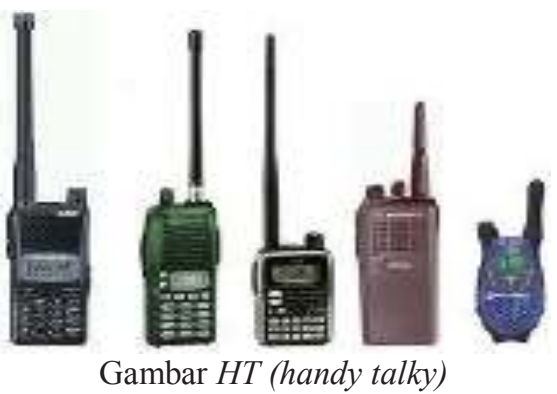

2) Penerangan (Senter)

Penerangan sangat penting untuk menunjang pengawasan pada malam hari untuk memberi cahaya agar dapat melihat pergerakan, orang, benda atau prahu yang mendekati kapal. Penerangan geladak berfungsi sebagai pengawasan dan membantu dalam penglihatan dalam malam hari, personil dinas jaga juga dilengkapi dengan senter yang berfungsi untuk menyorot sekeliling kapal dan untuk memberi penerangan di deck agar personil jaga tidak terjatuh karena tersandung gading-gading kapal. Senter yang digunakan harus aman dalam situasi dan kondisi sesuai dengan muatan yang dibawa agar tidak menimbulkan panas yang dapat meyebabkan bunga api yang memicu kebakaran pada kapal tanker.

Masalah yang terjadi di atas kapal sehubungan dengan senter adalah jumlah senter yang sedikit yang sesuai persyaratan yang diperbolehkan digunakan di kapal tanker, senter yang mengalami kerusakan pada bolam lampu yang mati, dan per tempat baterai yang berkarat. 
Upaya yang dilakukan adalah dengan memperbaiki senter yang rusak, dengan mengganti bolam lampu yang baru, mengganti per tempat meletakkan baterai, membuat permintaan barang ke kantor dan membeli senter yang baru yang sesuai ketentuan di kapal tanker agar jumlahnya memadai dalam proses pelaksanaan dinas jaga. Menyimpan sparepart bolam lampu, per, baterai dan senter baru agar sewaktu-waktu senter rusak dapat segera diperbaiki dan diganti dengan senter yang baru.

\section{3) Pentungan}

Pentungan biasanya digunakan oleh polisi, security dan hansip untuk membela diri dari penjahat yang hendak melawan. Keberadaan pentungan di atas kapal sangat penting untuk melindungi diri penjahat. Bahan pembuat dari pentungan yang keras dan tumpul berfungsi untuk melumpuhkan penjahat tidak untuk membunuh.

Pentungan yang tidak ada di atas kapal sebagai alat pelindung diri personil dinas jaga adalah hal yang fatal dan membahayakan bagi keselamatan personil dinas jaga yang berada di deck yang bertatap muka langsung dengan orang atau penjahat di lapangan.

Hal yang harus dilakukan adalah dengan membuat permintaan barang ke kantor atau dengan membeli pentungan tersebut ditempat peralatan satpam/kepolisian. Disesuaikan jumlah personil jaga dan menyediakan spare di store agar ada cadangan apabila sewaktuwaktu hilang atau rusak.

b. Perbaikan dan penyediaan CCTV oleh kontraktor
Closed Circuit Television (CCTV) adalah merupakan sebuah sistem komputer menggunakan video kamera untuk menampilkan dan merekam gambar pada waktu dan tempat dimana perangkat tersebut terpasang. CCTV adalah singkatan dari kata Closed Circuit Television, yang artinya menggunakan sinyal yang bersifat tertutup atau rahasia, tidak seperti televisi biasa pada umumnya yang merupakan broadcast signal. Closed Circuit Television (CCTV) digunakan untuk pelengkap sistem keamanan yang dapat membantu kontrol keamanan dan juga dapat dipasang di berbagai lokasi seperti di anjungan, kamar mesin, haluan, buritan lambung kiri dan kanan kapal. Rekaman CCTV dapat diulang kembali dapat dijadikan barang bukti apa bila kapal mengalami suatu kejadian atau tindakan kriminal yang mengancam keamanan di atas kapal.

CCTV yang ada di atas kapal sering mengalami kerusakan. seperti motor kamera yang berputar-putar tidak terkontrol, CCTV yang mati, monitor yang gambarnya kabur dan kontrol CCTV yang tidak berfungsi dengan baik menyebabkan fungsi CCTV sebagai peralatan keamanan kurang maksimal.

Hal yang harus dilakukan terkait masalah CCTV adalah dengan membuat laporan yang dikirim ke kantor selanjutnya kantor memanggil kontraktor yang memasang untuk mengecek dan memperbaiki kerusakan yang terjadi terkait dengan CCTV, perwira mengecek ulang perbaikan yang dilakukan oleh kontraktor agar CCTV dapat digunakan. CCTV masih dalam garansi jadi pihak 
kapal tidak perlu mengeluarkan biaya untuk perbaikan.

2. Penerapan ISPS Code yang tidak maksimal

Penyelesaian masalah dari penerapan ISPS Code adalah pertama pengawasan, pembuatan checklist dan dilaksanakan training atau pengarahan kepada crew. Kedua penambahan personil yang melakukan dinas jaga.

a. Pengawasan, pembuatan checklist dan dilaksanakan training atau pengarahan kepada crew

Untuk meningkatkan keamanan maka kapal harus menerapkan ISPS Code dimanapun kapal berada di setiap pelabuham. Dalam melaksanakan ISPS Code maka harus ada managemen keamanan (Security Management) kapal yang baik. Manajemen artinya mengurus, mengelola, mengendalikan, mengusahakan, memimpin agar dapat teroganisasi dan lebih evektif dalam menjaga dan mengamankan kapal. Pemilik atau operator kapal yang mengoperasikan kapal untuk ukuran tertentu sebagaimana dimaksud Pasal 170 ayat 1 undangundang tersebut butir 1 di atas harus memenuhi persyaratan manajemen keamanan kapal. Kapal yang telah memenuhi persyaratan manajemen keamanan kapal sebagaimana dimaksud ayat 1 diberi sertifikat. Sertifikat Manajemen Keamanan Kapal sebagaimana dimaksud pada ayat 2 berupa Sertifikat Keamanan Kapal Internasonal (International Ship Security Certificate/ISSC). Perusahaan Pelayaran sebagaimana dimaksud ayat 2 di atas adalah sebagai organisasi yang telah memikul tanggung jawab atas pengoperasian kapal dan telah menyetujui untuk melaksanakan semua kewajiban dan tanggung jawab yang diwajibkan sebagaimana yang ditentukan Bab XI-2 Bagian A ISPS Code 2002.

Perwira keamanan kapal ship security officer (SSO) adalah personil di atas kapal, yang bertanggung jawab kepada nakhoda, yang ditunjuk oleh Perusahaan sebagai penanggung jawab terhadap keamanan kapal, termasuk implementasi dan pemeliharaan dari rancangan keamanan kapal dan untuk berkoordinasi dengan petugas keamanan perusahaan dan petugas keamanan fasilitas pelabuhan.

1) Pada keamanan tingkat siaga I, aktivitas yang harus dilaksanakan dengan melalui cara-cara yang tepat, pada semua kapal dengan berpedoman pada petunjuk pelaksanaan yang terdapat pada bab XI-2 dan bagian A serta bagian B ISPS Code, dalam rangka mengidentifikasi dan mengambil tindakan pencegahan terhadap insiden keamanan.

2) Pada tingkat siaga 2 tindakan pencegahan tambahan, yang ditetapkan dalam pedoman khusus ini harus diterapkan untuk masing-masing kegiatan secara terinci sebagaimana yang dimaksud huruf B tersebut di atas dengan memperhatikan petunjuk pelaksanaan yang terdapat pada bagian B ISPS Code.

3) Pada tingkat siaga 3 tindakan pencegahan khusus lebih lanjut, yang ditetapkan dalam rancangan masing-masing kegiatan secara terperinci sebagaimana yang dimaksud huruf $b$ tersebut di atas.

Yang terjadi di kapal MT. Sei Pakning pada saat pelaksanaan dinas jaga di pelabuhan Tanjung Perak Surabaya para personil dinas jaga tidak melakukan prosedur ISPS 
Code dengan benar, personil dinas jaga tidak melakukan pemeriksaaan menyeluruh terhadap loading master, surveyor dan para buruh yang memasang loading up yang datang ke kapal, pengecekan barang bawaan, memastikan barang bawaan yang naik ke atas kapal tidak ada barang yang berbahaya, pencocokan identitas diri, KTP ataupun passport dengan orang yang naik di atas kapal dan identitas ditinggal dan diganti dengan visitor card yang disesuaikan dengan keperluan dari setiap tamu yang naik di atas kapal. pengecekan dengan metal detektor disertai perabaan memastikan dalam tubuh tidak ada benda, berbahaya dan barang terlarang naik ke atas kapal. Barang berbahaya dan terlarang tidak boleh naik ke atas kapal barang tersebut diamankan oleh pihak kapal agar hal-hal yang tidak diinginkan tidak terjadi di atas kapal.

Hal-hal yang harus dilakukan berkaitan dengan masalah kurang efektifnya penerapan ISPS Code adalah dengan melaksanakan pengawasan oleh perwira kapal, memberikan pengarahan rutin atau training kepada crew kapal agar pengetahuan tentang ISPS Code lebih meningkat, membuat checklist terhadap semua kegiatan di atas kapal, menempel poster-poster tentang ISPS Code.

b. Penambahan personil yang melakukan dinas jaga

Penambahan personil dinas jaga di daerah rawan adalah hal yang sangat penting dalam pelaksanaan dinas jaga, jumlah personil dinas jaga di daerah rawan harus ditambah mengingat daerah yang yang mempunyai security level yang meningkat dibanding daerah aman atau normal, harus diadakan pengawasan lebih maksimal karena ancaman yang meningkat, agar tidak ada kejadian atau hal yang dikhawatirkan terjadi di atas kapal.

Hal-hal yang harus dilakukan berkaitan dengan masalah kurang efektifnya penerapan ISPS Code adalah dengan menambah personil dinas jaga untuk membantu dalam pelaksanaan dinas jaga, pengawasan dan meningkatkan keamanan di kapal.

Bagaimana upaya yang harus dilakukan untuk meningkatkan keamanan di daerah rawan?

1. Penjadwalan terhadap perawatan alat penunjang keamanan.

Jadwal perawatan yang rutin harus dilaksanakan agar alat-alat tersebut terpelihara dengan baik. Hal ini tentunya sangat dibutuhkan perencanaan yang baik dalam melaksanakan kegiatan tersebut. Perawatan secara berkesinambungan ini tentu sangat diperlukan untuk menghindari kemerosotan fungsi alat yang disebabkan karena usia atau faktor yang lainnya. Maka dari itu menurut Planed Maintenance System (Sistem Perawatan Terencana) perlu adanya pelaksanakan perawatan pada waktu-waktu yang dijadwalkan :

a. Perawatan HT (handy talky)

b. Perawatan Penerangan (senter)

c. Perawatan berkala Perlengkapan CCTV

2. Meningkatkan pengetahuan dan kesadaran tentang keamanan

Tugas nakhoda dan mualim tidak hanya mengacu pada pekerjaan operasional kapal. Tetapi mereka juga dituntut untuk memberi contoh, sebagai panutan dan mengarahkan 
tentang pelaksanaan dinas jaga yang baik dan benar. Dari segi pendidikan nakhoda dan Mualim tentu mempunyai pengetahuan lebih tentang dinas jaga, oleh karena itu, mereka wajib memberi arahan dan pengertian yang jelas tentang pentingnya pelaksanaan dinas jaga yang baik dan benar agar tercipta keamanan dan keselamatan jiwa, kapal dan muatan. Menanamkan tentang pentingnya keamanan dan keselamatan jiwa kapal dan muatan bukanlah hal yang mudah. Dengan memberi pengertian akan pentingnya pelaksanaan dinas jaga yang baik agar tercipta keamanan dan keselamatan jiwa, kapal dan muatan, crew kapal tentu akan melaksanakan dinas jaga dengan sebaik-baiknya.

Upaya meningkatkan kesadaran crew kapal dalam melaksanakan dinas jaga. Mualim I yang bertanggung jawab terhadap pembuatan jadwal dinas jaga dan Mualim II selaku SSO yang bertanggung jawab terhadap keselamatan kapal harus bekerja sama untuk menciptakan suasana kapal yang aman.

3. Menerapkan ISPS Code di atas kapal Untuk meningkatkan keamanan maka kapal harus menerapkan ISPS Code dimanapun kapal berada di setiap pelabuhan. Dalam melaksanakan ISPS Code maka harus ada manajemen keamanan (Security Management) kapal yang baik. Manajemen artinya mengurus, mengelola, mengendalikan, mengusahakan, memimpin agar dapat teroganisasi dan lebih efektif dalam menjaga dan mengamankan kapal. Pemilik atau operator kapal yang mengoperasikan kapal untuk ukuran tertentu sebagaimana dimaksud Pasal 170 ayat (1) undang-undang tersebut butir 1 di atas harus memenuhi persyaratan manajemen keamanan kapal. Kapal yang telah memenuhi persyaratan manajemen

4. Pengawasan langsung di lapangan terhadap pelaksanaan dinas jaga oleh perwira.

Dalam kegiatan pelaksanaan dinas jaga harus ada kontrol dan pengawasan agar dalam pelaksanaan dinas jaga dapat dilakukan dengan baik. Mualim I sebagai penanggung jawab pelaksana dinas jaga dan mualim II sebagai perwira keamanan sebaiknya turun langsung di lapangan dan memeriksa pelaksanaan dinas jaga yang dilakukan oleh regu jaga secara langsung. Mualim berhak menegur apabila dalam pelaksanaan dinas jaga dilakukan dengan tidak serius atau seenaknya sendiri oleh regu jaga. Sehingga pelaksanaan dinas jaga dapat dilaksanakan dengan baik dan tercipta keamanan di atas kapal.

5. Komunikasi yang baik

Tingkatkan komunikasi serta koordinasi antara kapal dan pelabuhan. Pihak kapal dan pelabuhan harus ada komunikasi dan koordinasi yang baik tentang prosedur keamanan yang harus dijalankan untuk mencegak ancaman keamanan. Selain itu pihak kapal sendiri juga harus ada komunikasi dan koordinasi yang baik antara semua crew baik perwira dan bawahan, antara personil dinas jaga, departemen deck dan mesin dan crew kapal MT. Sei Pakning. Tingkatkan pula hubungan yang harmonis antara perwira dan bawahannya dengan cara sering mengadakan acara pertemuan rutin 
Analisis Peningkatan Dinas Jaga di Daerah Rawan Guna Meningkatkan Keamanan

Pada Kapal MT. Sei Pakning

Dwi Antoro a, Sri Purwantini dan M. Arif Ikhsannudin ${ }^{\mathrm{c}}$

di atas kapal mengangkat masalahmasalah yang terjadi di kapal. Juga dengan cara saling bertukar informasi baik dari perwira ke bawahan ataupun dari bawahan ke perwiranya. Sehingga para bawahan tidak merasakan adanya jurang pemisah yang selama ini menjadikan jarak diantara perwira dan bawahannya. Selama ini para bawahan akan cenderung mendekati perwira atau orang-orang yang bisa diajak bertukar pikiran dan informasi dengan mereka.

\section{KESIMPULAN}

Kesimpulan yang dapat diambil dari penelitian tentang "Analisis peningkatan dinas jaga di daerah rawan guna meningkatakan keamanan pada kapal MT. Sei Pakning" adalah :

1. Pelaksanaan dinas jaga di daerah rawan tidak maksimal karena peralatan penunjang keamanan yang kurang, disebabkan karena tidak tersedianya handy talky (HT), senter, pentungan di atas kapal yang menjadi peralatan penunjang keamanan dan CCTV di atas kapal yang mengalami trouble disebabkan karena pemasangan CCTV yang tidak sempurna oleh kontraktor.

2. Penerapan ISPS Code di atas kapal ketika berada di daerah rawan tidak berjalan maksimal disebabkan karena pelaksanaan dinas jaga yang tidak sesuai prosedur ISPS Code dan jumlah personil dinas jaga yang kurang dalam pelaksanaan dinas jaga.

Dalam kesempatan ini penulis juga akan memberikan saran-saran, diharapkan dalam menjadi masukan dalam pelaksanaan dinas jaga di daerah rawan dapat berjalan secara maksimal adapun saran-saran tersebut adalah:
1. Seharusnya perusahaan pelayaran PT. Pertamina (Persero) menyediaan peralatan penunjang keamanan seperti handy talky (HT), senter, dan pentungan kepada kapal milik karena peralatan penunjang keamanan sangat penting dalam menunjang pelaksanaan dinas jaga dalam menciptakan keamanan di kapal.

2. Sebaiknya pihak kapal segera melaporkan masalah CCTV yang trouble kepada kantor PT. Pertamina (Persero) agar perusahaan segera memangil kontraktor agar segera dilakukan perbaikan dan penyediaan CCTV oleh kontraktor agar mempermudah dalam pengawasan. CCTV sangat membantu dalam pelaksanaan dinas jaga karena fungsi CCTV yang sangat penting dapat ditempatkan di lokasi-lokasi yang diinginkan dan mudah dalam pengawasannya.

3. Seharusnya Perwira melaksanakan pengawasan terhadap crew, pembuatan checklist dan dilaksanakan training atau pengarahan kepada crew sehingga crew dapat mengerti dan memahami tentang prosedur ISPS Code yang benar sehingga crew dapat melaksanakan tugas dan tanggung jawab sesuwai prosedur ISPS Code.

4. Sebaiknya crew kapal untuk ikut membantu dalam pelaksanaan dinas jaga sehingga jumlah personil dinas jaga yang melaksanakan dinas jaga mencukupi sehingga dalam pelaksanaan dinas jaga lebih meningkat, pengawasan terhadap bagian kapal dan lingkungan kapal lebih baik. Penjagaan kapal lebih detail dan kontrol terhadap bagian kapal lebih baik, sehingga akan memaksimal pelaksanaan dinas jaga sehingga akan menciptakan keamanan di atas kapal. 


\section{DAFTAR PUSTAKA}

Cipto. 2007. Hubungan Internasional di Asia Tenggara. Yogyakarta: Pustaka Pelajar

Collins, Alan. 2007. Contemporary Security Studies. UK: Oxford University Press

Supardi. 2008. Metodologi Penelitian Ekonomi dan Bisnis. Yogyakarta: UII Press

Margono. 2008. Metodologi Penelitian Pendidikan. Bandung: Remaja Rosdakarya

Tim Penyusun Kamus Pusat Indonesia. 2008. Kamus Bahasa Indonesia. Jakarta: Depdikbud Balai Pustaka

Sugiyono. 2009. Metode Penelitian Kuantitatif, Kualitatif dan $R \& D$. Bandung: Alfabeta

Noor, Juliansyah. 2009. Metodologi Penelitian : Skripsi, Tesis, Disertasi dan Karya Ilmiah. Jakarta: Kencana

Jogiyanto. 2010. Analisis dan Desain Sistem Informasi, Edisi IV. Yogyakarta: Andi Offset

IMO. 2010. STCW a Guide For Seafarers Talking Into Account the 2010 Manila. London: CPI Group (United Kingdom)

Subanrijo, Djoko. 2011. Tugas Jaga. Semarang: Patriangga

IMO. 2012 .Guide to Maritimme Security and The ISPS Code. London: CPI Group (United Kingdom)

Wiratna. 2014. Dasar dan Teknik Reseach. Bandung: Tarsito
IMO. 2016. Internasional Ship and Port Facility Security Code. London: CPI Group (United Kingdom) 